$\xi=-1$

\title{
Flash Flood Warning Sub-Systems for Rural Africa
}

\author{
Stella N. Mbau ${ }^{1 *}$, Vinesh Thiruchelvam ${ }^{2}$ \\ ${ }^{I}$ Faculty of Computing and Technology, Asia Pacific University of Technology and Innovation, Kuala Lumpur, Malaysia \\ ${ }^{2}$ Faculty of Computing and Technology, Asia Pacific University of Technology and Innovation, Kuala Lumpur, Malaysia \\ *Corresponding authorE-mail: tp042071@mail.apu.edu.my
}

\begin{abstract}
This paper aims to present the need for sub-systems in rural Africa for real-time warning delivery. It has been reported in previous studies, that Sub-Sahara Africa lacks weather radars. This means that there are no real-time early warnings presenting a gap in knowledge that this study aims to address. This is done through the following objective; to examine the relationship between variables in the study and therefore, establish whether sub-systems are a significant variable in flash flood warning systems for rural Africa. The variables to be examined are; the independent variable (existing warning system), the dependent variable (early warnings), the moderator variable (ancillary elements) and the mediator variable (sub-systems). This is investigated through a closed-ended questionnaire that is administered to a sample of meteorologists whose email addresses are available on the World Meteorological Organization's expert database. The target sample is determined through the G*Power application. The data is analyzed on SPSS. Variables in the study are found to be correlated after conducting a Pearson's correlation test. Using PROCESS allows for the testing of various models where moder ation is confirmed. A moderated mediation model is also confirmed. The results confirm that sub-systems are significant enough to be developed for rural Africa.
\end{abstract}

Keywords: Early warnings; Flash Floods; Rural Africa; Sub-Systems.

\section{Introduction}

It is reported that there is a big correlation between the frequency of natural disasters and global warming [1]. Natural disasters are more periodic and some of the weather events, like flash floods, can therefore be predicted with the help of infrastructure. River flooding in Africa is the focus of this paper in order to find solutions that foster real time warning delivery. This would then lead to resilience of rural communities in Africa. Resilience is defined as the ability of a community exposed to natural disaster to resist and recover from the disaster in an efficient manner. It is therefore important for communities involved to be well informed of such disasters and prepared to respond effectively [2].

In the least developed countries, such disasters have a variety of negative effects including socio-economic development. A rapid population growth in these countries also leads to an increased number of vulnerable people. The Hyogo Framework for Action 2005- 2015 emphasized the need for Early Warning Systems [3]. This was reiterated in the 2030 Agenda for Sustainable Development Goals.

Africa is said to be vulnerable to flash floods because of the lack of weather radars [4]. For this study Kenya is of interest as a technology hub in Sub-Sahara Africa [5]. Its influence on innovation for rural Kenya will help inform the sub-system to be developed for Tana River County and rural Africa in general. This will address the gap in knowledge of real time warnings in rural Africa [4].

The problem of flash floods and the need for adaptive measures for resilience is well espoused in the climate change resilience theory [6]. To address vulnerability of communities in rural Africa, resilience infrastructure (the sub-systems in this paper) will be studied. These Early Warning Systems should have the following functions to support real time decision making; observation systems for data collection, forecast capacity and management of data, capacity to analyze and interpret forecasts as well as communication tools for the dissemination of warnings [3]. These are also discussed in the World Meteorological Organization's Flood Forecasting Initiative, and are therefore adopted as variables for this study [7].

From a review of flash flood warning systems and sub-systems, the following conceptual framework was drafted for this study. The framework was tested via a questionnaire to examine whether the same relationships could be applied to a rural African context.

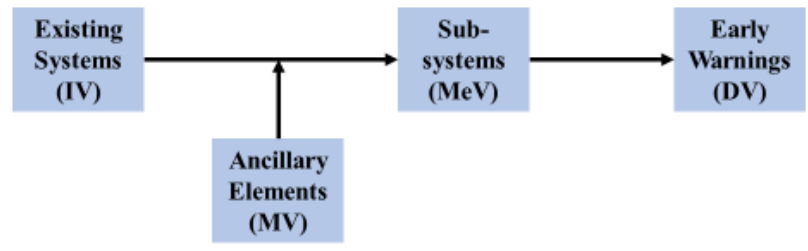

Fig. 1: Conceptual Framework [7]

\section{Research Methods}

The study area for this research was Tana River County found at the coast of Kenya. It has a population of 240,075 as recorded in the 2009 census [8]. Questionnaires were used as the data collection tool. The purpose of the questionnaire was to determine the significance of sub-systems for rural Africa. They were used to obtain data from a sample of experts in Africa that could be analysed for generalizability [9]. A sub-system would then be developed for Tana River County if duly supported by findings from 
this questionnaire. The same sub-system would be proposed for rural Africa.

The questionnaire was used as a data collection tool because it is familiar to most people and therefore easy to administer. It had 55 closed-ended questions to be scored on a 5-point likert scale where: $1=$ strongly disagree, $2=$ disagree, $3=$ neutral, $4=$ agree and $5=$ strongly agree [9]. Africa has 17 river flooding countries as reported in [10]. These countries are; Burkina Faso, Burundi, Cameroon, Central African Republic, Chad, Democratic Republic of Congo, Ethiopia, Ghana, Guinea, Kenya, Mali, Niger, Nigeria, Rwanda, Somalia, South Sudan and Sudan.

Meteorological data was sought for this study and therefore through the World Meteorological Organisation's expert database, emails of experts based in the 17 countries mentioned above were extracted. Out of 809,708 experts were found to have available email addresses. The $\mathrm{G}^{*}$ Power version 3.1.9.2 application was used to determine an appropriate sample size [11]. With a medium effect size of 0.15 ; alpha value of 0.05 ; and power of 0.80 , a sample size of 85 was arrived at. The data collected was assumed to have internal validity because the pool of respondents was made of experts.

\section{Data Analysis}

The following is a report of data analysed for the objective of this paper; to examine the relationship between variables in the study and therefore establish whether sub-systems are a significant variable in flash flood warning systems for rural Africa. SPSS was used to run both descriptive and inferential tests on data collected. 173 respondents filled the web-based questionnaire for this study bringing the response rate to $24.44 \%$. Data was prepared as follows.

Firstly, accuracy was checked by running frequency tables to have a general feel to the data. At this point some values were found to be missing [12]. From the charts below, sub-systems are seen to have recorded more neutral values than the other variables. The existing system (IV) scored 50 "disagree" responses which means that the systems themselves could use enhancements. Ancillaries also reported values that were proof that there is room for improvement. The early warnings (DV) recorded encouraging responses but also illustrated neutrality that could be addressed with the improvement of the other variables. These results were investigated further using inferential tests.

Table 1: Frequency tables for variables

$\begin{array}{lccccc}\text { Existing systems (IV) } & \begin{array}{c}\text { strongly } \\ \text { disagree }\end{array} & \text { disagree } & \text { neutral } & \text { agree } & \begin{array}{c}\text { Strongly } \\ \text { agree }\end{array} \\ & 21 & 50 & 40 & 45 & 14 \\ \text { Sub-systems } & \begin{array}{l}21 \\ \text { strongly } \\ \text { disagree }\end{array} & \text { disagree } & \text { Neutral } & \text { agree } & \begin{array}{c}\text { Strongly } \\ \text { agree }\end{array} \\ & 28 & 31 & 61 & 32 & 11 \\ \text { Ancillaries } & \text { strongly } & \text { disagree } & \text { Neutral } & \text { agree } & \text { Strongly } \\ & \begin{array}{l}\text { disagree } \\ 28\end{array} & 46 & 51 & 31 & 14 \\ & \text { strongly } & \text { disagree } & \text { neutral } & \text { agree } & \text { Strongly } \\ \text { Early warnings (DV) } & \text { disagree } & & & & \text { agree } \\ & 14 & 30 & 45 & 65 & 16\end{array}$

Secondly, missing values analysis was carried out. Data was transformed and recoded after which there were 162 valid respondents remaining. Thereafter, constructs were grouped into their respective variables [12]. Thirdly, a Cronbach's alpha test was run to check the reliability of the scale used. This was found to be $\alpha=.968$ [13].

\section{Moderation and Moderated Mediation Analysis}

A moderation effect was investigated [14]. Prior to this, the following assumption were met. First, variables had to be continuous and on a likert scale. Secondly, by running a regression model, there had to be no outliers. This was carried out using the Mahalanobis, Cook's and leverage distance. 3 respondents were found to be outliers and were therefore deleted bringing the number of respondents to 159 . Thirdly, the data had to be normally distributed. For this, histograms were used. As shown below using a normal curve, normality is confirmed.

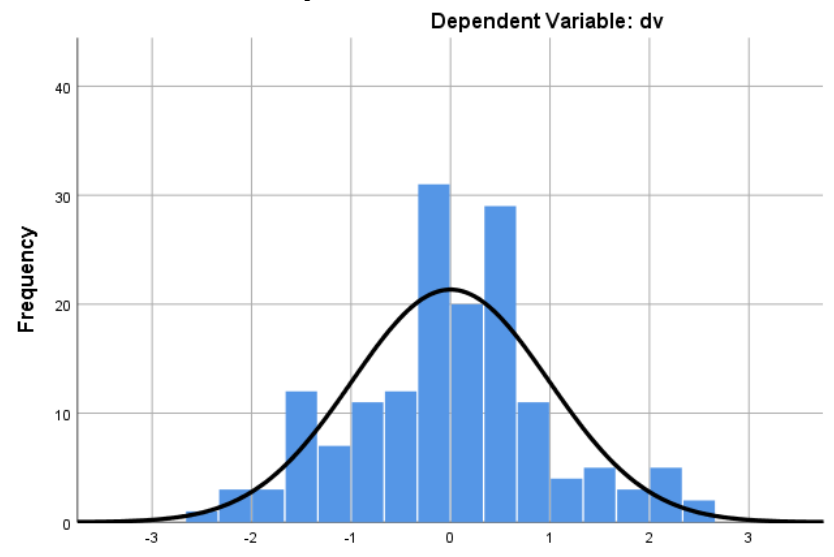

Fig. 2: Normality histogram of the regression standardized residual

After this, linearity was tested by running a normal P-P plot. The results showed the dots centred around the line thus confirming linearity. Homogeneity was confirmed because results of the regression standardized residual centred around zero. Homoscedasticity was however not confirmed because the dots did not form a blob [12].

Finally, correlation among variables was examined using the Pearson's correlation test $[15,16]$. The results showed that the variables were significantly correlated; moderate positive correlations were established between the existing system (IV) and the subsystems $(r=.673, p<.001)$, ancillary elements and the sub-systems $(\mathrm{r}=.655, \mathrm{p}<.001)$ and a between the existing system and ancillary elements $(r=.623, p<.001)$. Additionally, existing systems (IV) and early warnings registered a weak positive correlation $(\mathrm{r}=.356$, $\mathrm{p}<.001)$. To ensure that there would be no multicollinearity, PROCESS version 3.0 (2018) written by Andrew F. Hayes [11] for SPSS was used to run various models of moderation, mediation and moderated mediation.

Table 2: Table of Correlation between variables

\begin{tabular}{|c|c|c|c|c|c|}
\hline \multirow[t]{3}{*}{ iv } & Pearson Correlation & 1 & $.673^{\text {** }}$ & $.623^{* *}$ & $.356^{* \star}$ \\
\hline & Sig. (2-tailed) & & .000 & .000 & .000 \\
\hline & $\mathrm{N}$ & 170 & 159 & 170 & 170 \\
\hline \multirow[t]{3}{*}{ sub } & Pearson Correlation & $.673^{* *}$ & 1 & $.655^{* *}$ & $.474^{* *}$ \\
\hline & Sig. (2-tailed) & .000 & & .000 & .000 \\
\hline & $\mathrm{N}$ & 159 & 159 & 159 & 159 \\
\hline \multirow[t]{3}{*}{ anci } & Pearson Correlation & $623^{* *}$ & $.655^{* *}$ & 1 & $.636^{* *}$ \\
\hline & Sig. (2-tailed) & .000 & .000 & & .000 \\
\hline & $\mathrm{N}$ & 170 & 159 & 170 & 170 \\
\hline \multirow[t]{3}{*}{$\mathrm{dv}$} & Pearson Correlation & $.356^{\circ *}$ & $.474^{* *}$ & $.636^{* *}$ & 1 \\
\hline & Sig. (2-tailed) & .000 & .000 & .000 & \\
\hline & $\mathrm{N}$ & 170 & 159 & 170 & 170 \\
\hline
\end{tabular}

Using PROCESS to examine moderation the significance values of the interaction term, as well as the significance level of the R2 change are checked. To confirm mediation, the following pointers are checked to confirm mediation; the first and second models generated from PROCESS should be significant. Bootstrapped confidence intervals should also not contain zero for the confirmation of mediation. To illustrate the direction of moderation as con- 
firmed, the Johnson Neyman test generates values used to run a syntax whose output is a graph.

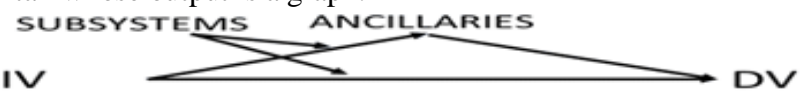

Fig. 3: Model 8 with Ancillaries as the Mediator

From PROCESS the following output is obtained for the Model 8 as illustrated in figure 3 above. The first model; existing systems (IV) $\mathrm{p}<.000$, sub-systems (MV) $\mathrm{p}<.000$ and the interaction term $\mathrm{p}<.05$ are significant predictors of ancillaries $(\mathrm{MeV})$. In this case the $\mathrm{R} 2$ change (.0153) is also significant at $\mathrm{p}<.05$. The second model; existing systems (IV) $\mathrm{p}<.05$, ancillaries $(\mathrm{MeV}) \mathrm{p}<.000$, sub-systems (MV) $\mathrm{p}<.05$ and the interaction term $\mathrm{p}<.001$ are significant predictors of early warnings (DV). In this case the R2 change (.0187) is also significant at $\mathrm{p}<.001$. Indirect effect of existing systems (IV) on early warnings (DV) via ancillaries $(\mathrm{MeV})$ is greater than zero; the lower (.0003) and upper (.0022) confidence intervals do not contain zero. The above results confirm a moderated mediation relationship existing between the variables.

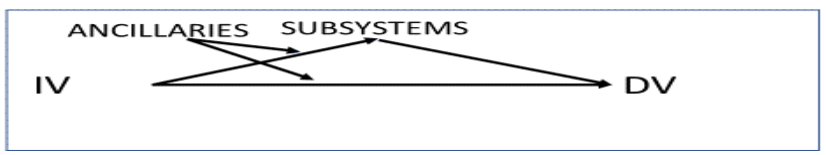

Fig. 4: Model 8 with Ancillaries as the Moderator

First model; existing systems (IV) $\mathrm{p}<.000$, ancillaries (MV) $\mathrm{p}<.01$ and the interaction term $\mathrm{p}<.01$ are significant predictors of subsystems $(\mathrm{MeV})$. In this case the R2 change (.0348) is also significant at $\mathrm{p}<.01$. Second model; existing systems (IV) $\mathrm{p}<.05$, subsystems $(\mathrm{MeV}) \mathrm{p}<.05$, ancillaries $(\mathrm{MV}) \mathrm{p}<.000$ and the interaction term $\mathrm{p}<.01$ are significant predictors of early warnings (DV). In this case the R2 change (.0135) is also significant at $\mathrm{p}<.01$. Indirect effect of existing systems (IV) on early warnings (DV) via ancillaries $(\mathrm{MeV})$ is greater than zero; the lower (.0001) and upper (.0021) confidence intervals do not contain zero. The above results confirm a moderated mediation relationship existing between the variables.

\section{Conclusion}

The following models were confirmed from the PROCESS models tested. Model 8, where the existing system (IV) affects ancillaries $(\mathrm{MeV})$ and then affects early warnings (DV), but both the existing system (IV) directly affects ancillaries and the existing system (IV) directly affects early warnings (DV) are moderated by sub-systems. Another version of Model 8 when ancillaries and sub-systems are swopped was also confirmed. This is where the existing system (IV) affects sub-systems (MeV) and then affects early warnings (DV), but both the existing system (IV) directly affects sub-systems and the existing system (IV) directly affects early warnings (DV) are moderated by ancillaries. The study objective, to examine the relationship between variables was accomplished as well as establishing sub-systems as a significant variable in flash flood warning systems for rural Africa.

PROCESS as used in this study, was found as a valuable tool because it enabled the testing of various models. These helped to meet the aim of this study, which was to examine variables and their relationships but most importantly, the significance of the relationship between sub-systems and the other variables. The most relevant model was found to be Model 8. It illustrates a moderated mediation and accommodates all the variables in the study. Descriptive results showed that the sub-systems variable is not well articulated and therefore the lack of definition as was seen in the neutral values. After running inferential tests however, it was confirmed that sub-systems are a significant variable. From the results, both ancillaries and sub-systems are significant enough to address the existing early warning delivery problem and the findings support the development of sub-systems for rural Africa.
In this paper, it is also recommended that community engagement be used as a platform to improve the ancillary elements variable. The best-fit model, out of the PROCESS models confirmed in this study, could be investigated further in future research. The subsystems for example, had a high score on the neutral scale. This means that with more awareness of sub-systems, data collected would lead to more accurate interpretation. your article.

\section{Acknowledgement}

We seek to express appreciation for the experts who took their time to respond to this survey. We also with to thank the WMO Permanent Representative of Kenya, also Director of the Kenya Meteorological Department, Peter Ambenje, who was gracious enough to acknowledge that the findings herein are a true reflection of rural Africa and real-time warnings.

\section{References}

[1] Harrison CG and Williams PR, "A systems approach to natural disaster resilience", Simul Model Pract Theory, (2016), available online: https://www.sciencedirect.com/science/article/pii/S1569190X16000277, last visit:09.05.2018

[2] Tyler S, Moench M, "A framework for urban climate resilience", Clim Dev, Vol.4, No.4, (2012), pp.111-126, available online: http://www.tandfonline.com/action/journalinformation?journalCode=tcl d20, last visit: 16.04.2018

[3] Venäläinen A, Pilli-Sihvola K, Tuomenvirta H, Ruuhela R, Kululanga E, Mtilatila L, "Analysis of the meteorological capacity for early warnings in Malawi and Zambia", Clim Dev, Vol.8, No.2, (2016), pp.190-196

[4] Hoedjes J, Kooiman A, Maathuis B, Said M, Becht R, Limo A, “A Conceptual Flash Flood Early Warning System for Africa, Based on Terre strial Microwave Links and Flash Flood Guidance", ISPRS Int J GeoInformation, Vol.3, No.2, (2014), pp.584-598, available online: http://www.mdpi.com/2220-9964/3/2/584/

[5] Workman D., "African Countries With The Most Tech Hubs Ranked", IT News Africa: Africa's Technology News Leader, available online: http://www.itnewsafrica.com/2017/06/african-countries-with-the-mosttech-hubs-ranked/

[6] Andersson-Sköld Y, Thorsson S, Rayner D, Lindberg F, Janhäll S, Jonsson A, "An integrated method for assessing climate-related risks and adaptation alternatives in urban areas", Clim Risk Manag, Vol.7, (2015), pp.31-50, available online: http://dx.doi.org/10.1016/j.crm.2015.01.003, last visited:16.04.2018

[7] Expert meeting: Improving the efficiency of flood forecasting services, Development of a Framework for the Assessment of Service Delivery Capabilities of Hydrological Services, (2013), http://www.wmo.int/pages/prog/hwrp/documents/FFI/FINALREPORT Expert meeting_EFFICIENCY FF-SERVICES 2013.pdf

[8] Tuckwood, C., \& Mutisya C, "Information and communications technology in peacebuilding: Lessons from Kenya's Tana Delta", Confl Trends, (2014)

[9] Sekaran, Uma and Bougie R, Research Methods For Business: A Skill Building Approach, John Wiley and Sons Inc, (2016), pp:19-351

[10] Kamga A, Buch M, Ly M, Ahamadou B, Musanganire A, Climate Services for Disaster Risks Reduction in Africa, (2017)

[11] Moderation, (2013), available http://orsp.kean.edu/documents/Moderation_Meditation.pdf

[12] Mensah S, Keung J, Bosu MF, Bennin KE, "Duplex output software effort estimation model with self-guided interpretation", Inf Softw Technol, Vol.94, (2018), pp.1-13

[13] Taber KS, "The Use of Cronbach's Alpha When Developing and Reporting Research Instruments in Science Education", Res Sci Educ, (2016), pp.1-24, available online: https://link-springercom.ezproxy.apiit.edu.my/content/pdf/10.1007\%2Fs11165-016-96022.pdf

[14] Arslan G, "Social Exclusion, Social Support and Psychological Wellbeing at School: A Study of Mediation and Moderation Effect", Child Ind Res, (2017), pp.16-22, available online: https://link-springercom.ezproxy.apiit.edu.my/content/pdf/10.1007\%2Fs12187-017-94511.pdf

[15] Polančič G, Jošt G, Heričko M, "An experimental investigation comparing individual and collaborative work productivity when using desktop and cloud modeling tools", Empir Softw Eng, Vol.20, (2015), pp.142175

[16] Zareen M, Razzaq K, Mujtaba BG, "Impact of Transactional, Transformational and Laissez-Faire Leadership Styles on Motivation: A Quanti- 
tative Study of Banking Employees in Pakistan", Public Organiz Rev, Vol.15, (2015), pp.531-549 